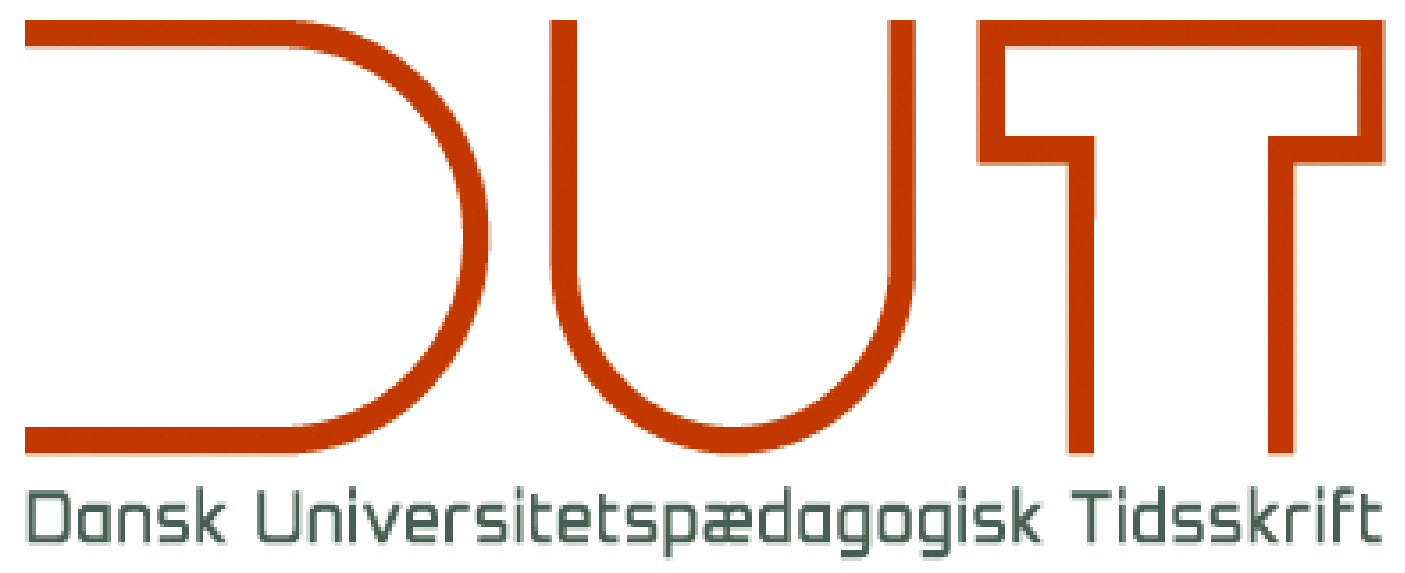

Tema

Fra data til beslutninger

Årgang 14 nr. 26 / 2019

Titel

Forfattere

Sidetal

Udgivet af

URL

Fremmedsprogsstuderendes overbevisninger om sproglæring: Før og efter profilsemesteret på kandidatstudiet

Susana Silvia Fernández

$5-22$

Dansk Universitetspædagogisk Netværk, DUN

> http://dun-net.dk/

Betingelser for brug af denne artikel

(c) Copyright
Denne artikel er omfattet af ophavsretsloven, og der må citeres fra den. Følgende betingelser skal dog være opfyldt:

- Citatet skal være i overensstemmelse med "god skik"

- Der må kun citeres „i det omfang, som betinges af formålet“

- Ophavsmanden til teksten skal krediteres, og kilden skal angives ift. ovenstående bibliografiske oplysninger.

DUT og artiklens forfatter 


\title{
Fremmedsprogsstuderendes overbevisninger om sprog- læring: Før og efter profilsemestret på kandidatstudiet
}

\author{
Susana Silvia Fernández ${ }^{\mathrm{a}, 1}$ \\ anstitut for Kommunikation og Kultur, Aarhus Universitet
}

Faglig artikel, fagfællebedømt

\begin{abstract}
Formålet med artiklen er at analysere, hvordan sprogstuderendes overbevisninger om sprogsyn og sproglæring bliver påvirket, når de vælger at følge en "underviserprofil" på deres kandidatstudie. Ved at vælge underviserprofilen på det næstsidste semester i kandidatuddannelsen kan den universitetsstuderende tone sit studium mod underviser-/lærerprofessionen med særligt fokus på undervisning i det danske gymnasium. Via faget "Undervisning i teori og praksis", som inkluderer gymnasiepraktik, får fremmedsprogsstuderende mulighed for at beskæftige sig med fremmedsprogsundervisning og didaktik fra et teoretisk og praktisk perspektiv. Gennem et casestudie af otte studerende fra et dansk universitet og på basis af metoder udviklet i forskningsfeltet om lærerkognition viser jeg, hvordan de studerendes viden og tanker, om hvordan man bedst underviser i og lærer fremmedsprog, udvikler sig i løbet af profilsemestret.
\end{abstract}

\section{Introduktion}

Forskningsfeltet om lærerkognition har eksisteret i over 30 år med fokus på både nye og erfarne lærere samt også til en vis grad på lærerstuderende. I de seneste ca. 15 år har der været en voksende interesse for fremmedsprogslærernes kognition, især takket være pionerarbejde af Simon Borg (fx 1998a,b; 2001; 2003), og det er lige præcis sproglærernes (rettere sagt sproglærerstuderendes) kognition, som er i fokus i nærværende artikel.

Målet med undersøgelserne inden for sproglærernes kognition er at skabe en bedre forståelse for, hvordan fremmedsprogslærernes indre liv, dvs. deres tanker, overbevisninger, viden og følelser, der relaterer sig til det de underviser i, påvirker deres praksis i klasseværelset og er med til at definere dem professionelt. Samtidig sigter man mod en forståelse af, hvor lærernes tanker og overbevisninger stammer fra, og hvordan de evt. påvirkes af uddannelse, efteruddannelse og andre kontekstuelle faktorer (Borg, 2003). I denne artikel vil jeg se nærmere på en bestemt målgruppe: danske kandidatstuderende inden for fremmedsprog, som har valgt at tone deres studium mod en karrierevej inden for de gymnasiale uddannelser (dvs. kommende gymnasielærere inden for fremmedsprog). Jeg vil undersøge deres kognition før, under og efter deres "profilsemester", dvs. det semester på kandidatstudiet, som er målrettet deres fremtidige undervisningserhverv. Ved at indsamle og analysere forskellige typer data (besvarelser fra refleksionsøvelser, gruppediskussioner, produktionsøvelser, refleksionsessays og interviews) vil jeg undersøge, hvordan profilsemestret påvirker disse studerendes kognition, og hvordan de selv oplever og reflekterer over semestret.

\footnotetext{
${ }^{1}$ Kontakt: romssf@cc.au.dk
} 
Artiklen er struktureret således, at der efter denne introduktion følger en kort præsentation af forskningsfeltet lærerkognition med særligt fokus på fremmedsprogslærere. Jeg vil beskrive de områder, der er blevet undersøgt, og de metoder, som typisk bliver anvendt. Derefter præsenteres kontekstuel information om, hvordan gymnasielærere bliver uddannet i Danmark efterfulgt af en detaljeret beskrivelse af det uddannelsesmodul, som bliver diskuteret i denne undersøgelse: profilsemestret for studerende fra humanistiske kandidatuddannelser på Aarhus Universitet, som ønsker at tone deres studium i en undervisningsorienteret retning (herunder undervisning i danske gymnasier). Når både den teoretiske og den kontekstuelle ramme er på plads, bliver den empiriske analyse præsenteret efterfulgt af en diskussion og konklusion.

\section{Lærerkognition som forskningsfelt}

Begrebet lærerkognition (teacher cognition) er blevet defineret af Borg $(2003$, s. 81) som "the unobservable cognitive dimension of teaching - what teachers know, believe and think". I forskningsfeltet om lærerkognition prøver man både at udforske og forstå lærernes viden og overbevisninger samt at finde ud af, hvordan disse påvirker deres praksis i klasseværelset. Interessen for lærerens tanker hænger sammen med en voksende forståelse for lærerens centrale rolle i undervisningen og for elevernes læringsproces (Hattie, 2003). Dette indebærer en overbevisning om, at læreren ikke blot mekanisk følger en opskrift til undervisningen, men er en beslutningstager, som er med til at designe, udføre og evaluere sin praksis i et cyklisk forløb - med Schöns (2001) ord: en "reflekterende praktiker".

I forskningen om lærerkognition har man fundet, at lærernes overbevisninger er hierarkisk organiseret med nogle tanker, som er stærkt rodfæstede, og andre, som er mere perifere og dermed nemmere at påvirke, fx ved uddannelse og efteruddannelse. Ofte er de mere centrale og rodfæstede tanker gamle, og de relaterer sig til almenpædagogiske forhold, såsom arbejdsformer eller elevernes motivation (Phipps \& Borg, 2009; Daryai-Hansen \& Henriksen, 2017). Når forskellige overbevisninger er i modsætning til hinanden, vil de centrale overbevisninger typisk tilsidesætte de mere perifere i lærerens praksis. Fx har Vijayavarathan (2017) fundet, at engelsklærere på Færøerne mente, at det er vigtigt at værne om elevernes motivation og selvværd, og at det også er vigtigt for læring at rette mundtlige fejl, men at de i praksis vælger ikke at rette mundtlige fejl af hensyn til elevernes følelser.

Forskningen har også vist, at de mest hårdføre tanker og meninger stammer fra lærernes egen erfaring som elever, hvad Lortie $(1975$, s. 67) har kaldt apprenticeship of observation. Disse tidlige kontakter med klasseværelset og sprogundervisning danner en stærk basis for lærernes egen konceptualisering af, hvad det betyder at lære og undervise i fremmedsprog. Disse tidlige modeller er stærke i de begyndende stadier af lærerprofessionen, og de kan sagtens fortsætte med at påvirke lærernes praksis gennem hele deres professionelle liv (Borg, 2006, s. 88).

Lærernes kognition er kompleks, ikke alene fordi tankerne kan være i konkurrence med hinanden, som vi lige har set, men også fordi mentale processer ikke umiddelbart er observerbare, og de kan være bevidste og ubevidste, samt affektive og personlige. Derfor er det nødvendigt at udforske kognitionen via forskellige metoder. Man kan både anvende kvantitative metoder til at undersøge teoretiske retninger, tanker og viden af et stort antal lærere via spørgeskemaer og tests, og man kan søge dybdegående indsigt i lærernes tanker via kvalitative instrumenter som interviews, fokusgruppeinterviews, dagbogsskrivning, biografiske beretninger, refleksionsessays, mindmaps osv. Desuden kan disse metoder kombineres, og de 
kan komplementeres med observationer af undervisningspraksis, således at de verbaliserede overbevisninger kan sammenlignes med klasseværelsesaktivitet.

Forskellige aspekter af sproglærerkognitionen har været i fokus i forskningsfeltet. Et veludforsket område har været forskellen mellem erfarne og uerfarne lærere, men også forskellige komponenter af sprogundervisning er blevet undersøgt. Ikke overraskende har lærernes overbevisninger vedr. grammatikundervisning været bedst repræsenteret (fx Borg 1998a, 1998b, 2001; Borg \& Burns 2008; Phipps \& Borg, 2009; Nishimuro \& Borg, 2013; Graus \& Coppen, 2016), men også overbevisninger om literacy (læsning og skrivning) (fx Graden, 1996; Meijer, Verloop \& Beijaard, 1999; Kuzborska, 2011) og det kulturelle fokus i sprogundervisning (fx Young \& Sachdev, 2001; Xiaohui \& Li, 2011; Fernández, 2015) har vakt opmærksomhed. Andre aspekter, såsom mundtlighed, lytteforståelse, anvendelse af teknologi, motivation for at lære fremmedsprog osv., er i mindre grad repræsenteret, men forskningsfeltet er produktivt, og flere og flere studier er med til at belyse tidligere uudforskede områder ( $\mathrm{i}$ Danmark se fx Vijayavarathan (2017) om mundtlighed, Kjærgaard (2018) om feedback og teknologi, samt Børsting (2018) om sproglæringsstrategier).

Som tidligere nævnt stammer lærerkognitionen i høj grad fra lærernes tidlige erfaringer med skolesystemet, men den bliver i større eller mindre grad også påvirket af andre faktorer: universitets- eller læreruddannelsen, efteruddannelsen, forskningen i sprogdidaktik, den sociale kontekst i form af kolleger, forældre, læreplaner osv., samt ikke mindst deres egen praktiske erfaring i klasseværelset (Borg, 2006). Samtidig er der ikke et én-til-én forhold mellem kognition (viden, tanker, overbevisninger) og praksis, da flere forskellige faktorer ofte kan gøre, at lærerne ikke agerer efter bedste overbevisning i deres pædagogiske beslutninger. Ministerielle retningslinjer, adgang til materialer, praktiske forhold i skolen, krav fra elever og forældre, eksamenskrav osv. kan være med til at påvirke lærernes pædagogiske beslutninger i en retning, som de ikke selv kan stå inde for. Denne uoverensstemmelse mellem kognition og praksis skal dog ikke nødvendigvis ses som udelukkende negativ, fx i tilfældet hvor lærerens holdninger er uegnede eller dysfunktionelle (Vijayavarathan, 2017). Uanset hvad kan forskningsfeltet om lærerkognition og dets inddragelse i læreruddannelsen være med til at hjælpe lærerne til at ransage deres overbevisninger og deres praksis, og disses indbyrdes forhold, for at få en bedre forståelse af egen professionelle ageren (Basturkmen, Loewen \& Ellis, 2004).

\section{Gymnasielæreruddannelsen i Danmark}

I Danmark findes der ikke deciderede gymnasielæreruddannelser, som i så mange andre lande, men der uddannes kandidater i gymnasiefag ( $\mathrm{fx}$ kandidater i historie, engelsk sprog, litteratur og kultur eller matematik), som så kan påtage sig funktionen som gymnasielærere, oftest med kompetence $i$ to og evt. flere fag. Efter endt kandidatstudium på universitetet og ved fast ansættelse på et gymnasium bliver de nye lærere tilmeldt det ét-årige "Pædagogikum ved de Gymnasiale Uddannelser", som består af en praktisk og en teoretisk pædagogikumuddannelse. Teoretisk pædagogikum, som styres af et konsortium af danske universiteter, omfatter 20 ECTS og inkluderer forskellige kurser og workshops i almen- og fagdidaktik². Praktisk pædagogikum, som hører under Undervisningsministeriet, vægter 40 ECTS og foregår på ansættelsesstedet, hvor en vejleder er med til at kvalificere kandidatens undervisning

\footnotetext{
${ }^{2}$ For information om det Teoretiske Pædagogikum, inkl. studieordningen, se Syddansk Universitet (u.d.)
} 
(Undervisningsministeriet, u.d.). Selvom det er meningen, at nyansatte gymnasielærere skal igennem Pædagogikumuddannelsen i deres første arbejdsår, er virkeligheden en anden for et stort antal gymnasielærere, da mange skal igennem en række vikarstillinger (muligvis i flere år), før de opnår en fast stilling og dermed adgang til Pædagogikumuddannelsen.

Derfor er det kærkomment, at der i de senere år har været en stigende tendens til, at universiteterne i løbet af kandidatstudierne tilbyder nogle uddannelseselementer (med vægtning på op til et halvt årsværk), hvor den studerende kan tone sit studium med henblik på en konkret karrierevej, herunder undervisning. Disse studieelementer, der målretter sig undervisning, inkluderer typisk kurser i almen- og/eller fagdidaktik samt en gymnasiepraktik. På denne måde tager man hul på de kommende gymnasielæreres pædagogiske uddannelse, før det egentlige pædagogikum, og i mens de stadig studerer på universitetet. Disse pædagogiske moduler kan være med til at udruste kandidaterne bedre til et lærerjob, da de supplerer kandidatens faglige viden med principper om almen- og fagdidaktik. Men de kan også bidrage til at kvalificere de studerendes karrierevalg, især under den praksisorienterede gymnasiepraktik, hvor den studerende kan prøve kræfter med en rigtig arbejdsplads.

På Aarhus Universitet udbydes "Profilfag", som beskrives som tvœrfaglige, arbejdsmarkedsorienterede fag til kandidatstuderende på de humanistiske uddannelser (Aarhus Universitet, u.d. a). Udbuddet af profiler kan variere lidt fra år til år. I efteråret 2017 blev der fx udbudt fire profiler: Kommunikationsprofil: web- og viral kommunikation; Kommunikationsprofil: Tillægsuddannelse i journalistisk formidling; Kulturformidlingsprofil; Special profile in international collaboration and intercultural competence; Underviserprofil.

Målet for nærværende analyse er - som tidligere nævnt - profilfaget "Underviserprofilen", og næste sektion handler derfor om denne.

\section{Underviserprofilen: Faget Undervisning i teori og praksis}

De studerende, der vælger denne profil, skal følge faget "Undervisning i teori og praksis", som vægter 20 ECTS og består af tre hovedelementer: Et kursus i almendidaktik (ca. 16 timers undervisning), hvor den studerende får information om gymnasiet og om elevernes forudsætninger samt bliver undervist i bl.a. pædagogiske grundbegreber og elevinddragende undervisningsformer; en gymnasiepraktik (20-30 klokketimer), hvor den studerende følger én eller flere lærere i ét eller flere gymnasiefag samt får mulighed for selv at undervise; et kursus i fagdidaktik (ca. 26-39 timers undervisning) som introducerer fagdidaktiske principper og teorier. Der er fem forskellige fagdidaktiske kurser at vælge imellem, afhængigt af hvilket undervisningsfag den studerende har: Danskfagets didaktik, Design- og kunstfagenes didaktik, Historiedidaktik, Religionsvidenskabelig fagdidaktik samt Second Language Acquisition and Pedagogy.

Faget "Undervisning i teori og praksis" med ovennævnte tre elementer bestås gennem en portfolioeksamen, som inkluderer en praktikrapport, et refleksionsessay, et undervisningsmodul, udviklet og revideret af den studerende, samt en synopsis til et mundtligt oplæg om et fagdidaktisk emne.

Det fagdidaktiske element "Second Language Acquisition and Pedagogy", som er i fokus i denne undersøgelse, kan vælges af alle studerende på Aarhus Universitet fra et fremmedsprogligt studium ( $f x$ engelsk, spansk, fransk, tysk, arabisk, kinesisk). 
Det bliver beskrevet således:

This course will introduce students to theories of second language acquisition (SLA) and to the practical application of findings from the study of SLA to actual classroom practice. The course is intended to help students gain a clearer understanding of what is most effective in second language learning and teaching, and what the effects are of different individual factors and contexts of learning. Students will understand their own past and future SLA progress and that of their own students from the perspective of theoretical and applied linguistics. (Aarhus Universitet, u.d. b)

Arbejdsformen i dette kursus er baseret på holdundervisning og gruppeopgaver, som løses hver uge, og som dels handler om bearbejdning af teoretisk fagdidaktisk litteratur og dels består af at udvikle, designe, præsentere og diskutere kommunikative tasks (dvs. problemorienterede kommunikative læringsaktiviteter) med fokus på forskellige aspekter af sprogundervisning (grammatik, ordforråd, udtale, interkulturel kompetence osv.).

Det er værd at nævne i denne kontekst, at de studerende ikke er forpligtede til at vælge underviserprofilen, selvom de har ambitioner om at blive undervisere. Udover at kunne vælge en af de andre profiler har de studerende også mulighed for i dette semester at følge undervisning på et udenlandsk universitet eller tage en erhvervspraktik enten i Danmark eller i udlandet. Dette betyder, at der er færdiguddannede kandidater, som ikke har haft dette pædagogiske element i deres studium, men som stadig har mulighed for at blive ansat på et dansk gymnasium.

\section{Empirisk undersøgelse}

I denne sektion vil jeg præsentere resultaterne fra en empirisk undersøgelse foretaget med et hold studerende fra Aarhus Universitet, som valgte Underviserprofilen og derunder Second Language Acquisition and Pedagogy som deres profilsemester. Holdet består af otte studerende, hvoraf syv læser engelsk og én læser tysk. Holdet er lille, da det drejer sig om et "forårshold" for studerende, som har haft et semesters propædeutik i deres studium og derfor er forsinkede/skæve i forhold til andre studerende (om efteråret er der normalt mellem 25 og 40 studerende). Det har været en bevidst beslutning at vælge et lille hold for at kunne foretage en kvalitativ analyse (se næste afsnit). Alle otte studerende på holdet har samtykket i at deltage i undersøgelsen ved at skrive under på en samtykkeerklæring. De er blevet anonymiseret således, at de hver har fået et identifikationsbogstav (fra A til H). Forskeren er også underviseren i det pågældende kursus.

\section{Data og metode}

Jeg har valgt at undersøge emnet kvalitativt (Merrian \& Tisdell, 2016), da jeg ønsker at opnå en dybdegående og kontekstualiseret forståelse af de deltagende lærerstuderendes tanker og viden om sproglæring og -undervisning. Med dette formål har jeg gennemført datatriangulering (Merrian, 2009) ved at indsamle og analysere forskellige typer data, som tilsammen er med til at belyse emnet så udtømmende som muligt.

For at belyse udviklingen i de deltagende studerendes overbevisninger omkring sproglæring og -undervisning har jeg derfor indsamlet alt det materiale, der blev produceret som en integreret del af undervisningen og eksamenen, samt andre data, som blev produceret specifikt med henblik på undersøgelsen. Data er således indsamlet ved hjælp af fem instrumenter: 1) Spørgeskema om sprogsyn: På første undervisningsdag udfyldte de studerende et spørgeske- 
ma med både lukkede spørgsmål (fempunkts Likert-skala) og tre åbne spørgsmål ${ }^{3}$ vedr. deres syn på sprog og sproglæring. Den lukkede del af spørgeskemaet kan ses i Tabel 1 og bidrager med en bred oversigt over de studerendes tanker. 2) Transskriptioner fra gruppediskussioner: På første undervisningsdag diskuterede de studerende deres besvarelser fra spørgeskemaet. På femte og tolvte undervisningsgang diskuterede de studerende deres besvarelser fra undervisningsgang nr. 1 på basis af deres nye viden. Disse tre sæt diskussioner blev optaget og transskriberet. 3) Gruppebesvarelser af i alt 10 ugeopgaver (delt af de studerende i Google docs), som de studerende arbejdede med hver uge som forberedelse til undervisningen i faget. 4) Individuelle besvarelser af eksamensportfolien. 5) Transskriptioner af forsinkede individuelle, semistrukturerede interviews (Kvale \& Brinkmann, 2009) foretaget ét år efter endt profilsemester.

\begin{tabular}{|c|c|c|c|c|c|}
\hline $\begin{array}{l}\text { Your ideas about language } \\
\text { learning and language teachers }\end{array}$ & $\begin{array}{l}1 \\
\text { (strongly } \\
\text { agree) }\end{array}$ & 2 & 3 & 4 & $\begin{array}{l}5 \\
\text { (strongly } \\
\text { disagree) }\end{array}$ \\
\hline $\begin{array}{l}\text { 1. Languages (L1 and L2) are } \\
\text { learnedmainly through imi- } \\
\text { tation }\end{array}$ & & ABDFGH & $E$ & C & \\
\hline $\begin{array}{l}\text { 2. People with high IQs are } \\
\text { good language learners }\end{array}$ & & $B$ & CDEFG & $\mathrm{AH}$ & \\
\hline $\begin{array}{l}\text { 3. The most important factor } \\
\text { for success in learning an } L 2 \\
\text { is motivation }\end{array}$ & AG & $\mathrm{BCDEH}$ & $\mathrm{F}$ & & \\
\hline $\begin{array}{l}\text { 4. Some people have a special } \\
\text { gift for language learning }\end{array}$ & $A C D$ & BEFGH & & & \\
\hline $\begin{array}{l}\text { 5. It is best to learn an } L 2 \text { in } \\
\text { the same way as you learn } \\
\text { your L1 }\end{array}$ & & $C D$ & $\mathrm{AHF}$ & BEG & \\
\hline $\begin{array}{l}\text { 6. The earlier an L2 is intro- } \\
\text { duced in school, the greater } \\
\text { the likelihood of success in } \\
\text { learning }\end{array}$ & CDF & ABEG & & $\mathrm{H}$ & \\
\hline $\begin{array}{l}\text { 7. Most of the mistakes made } \\
\text { by L2 learners are caused } \\
\text { by differences with the L1 }\end{array}$ & & $A C D$ & BEFGH & & \\
\hline
\end{tabular}

${ }^{3}$ Disse tre spørgsmål var: 1) Think of successful and unsuccessful experiences you have had of learning new languages. 2) How would you learn a new language assuming you had all the time and resources? 3) How would you teach someone your first language? 


\begin{tabular}{|c|c|c|c|c|c|}
\hline $\begin{array}{l}\text { 8. Learners' errors should be } \\
\text { corrected as soon as they } \\
\text { are made in order to pre- } \\
\text { vent the formation of bad } \\
\text { habits }\end{array}$ & A & $\mathrm{D}$ & BCFGH & $E$ & \\
\hline $\begin{array}{l}\text { 9. When L2 learners interact } \\
\text { freely (in groups or pairs), } \\
\text { they pick up each other's } \\
\text { mistakes }\end{array}$ & & $\mathrm{BEH}$ & ACDFG & & \\
\hline $\begin{array}{l}\text { 10. Students learn what they } \\
\text { are taught }\end{array}$ & & $\mathrm{CH}$ & ADG & BEF & \\
\hline $\begin{array}{l}\text { 11. Teachers should only use } \\
\text { the } L 2 \text { in the } L 2 \text { classroom }\end{array}$ & & $A D$ & BEFGH & $C$ & \\
\hline $\begin{array}{l}\text { 12. Teachers should avoid ex- } \\
\text { plicit discussion of grammar }\end{array}$ & & C & $E$ & ABDFGH & \\
\hline $\begin{array}{l}\text { 13. Language learners should } \\
\text { aim to sound like native } \\
\text { speakers }\end{array}$ & & $C D$ & $\mathrm{FH}$ & ABEG & \\
\hline $\begin{array}{l}\text { 14. Fluency is more important } \\
\text { than accuracy in L2 speech }\end{array}$ & & $\mathrm{AFH}$ & BCDEG & & \\
\hline $\begin{array}{l}\text { 15. L2 learners should take } \\
\text { responsibility for their own } \\
\text { learning }\end{array}$ & $\mathrm{EH}$ & ABCDFG & & & \\
\hline $\begin{array}{l}\text { 16. It is necessary to know the } \\
\text { L2 culture(s) in order to } \\
\text { speak an L2 }\end{array}$ & $\mathrm{BH}$ & $\mathrm{CF}$ & DEG & A & \\
\hline $\begin{array}{l}\text { 17. Learning an L2 is mostly } \\
\text { about learning grammar } \\
\text { rules }\end{array}$ & & & $\mathrm{DH}$ & $\mathrm{ABE}$ & CFG \\
\hline $\begin{array}{l}\text { 18. Sufficient L2 proficiency is } \\
\text { the most necessary to be- } \\
\text { come a qualified teacher }\end{array}$ & & $\mathrm{DH}$ & ABEFG & & C \\
\hline
\end{tabular}

Tabel 1. Spørgeskema med de studerendes besvarelser (de studerende er identificeret fra A til H) (Tilpasset fra Lightbown \& Spada 2011, s. xvii) 
Proceduren for dataanalysen bestod $i$ en tematisk- og indholdsanalyse af materialet (Dörnyei, 2007). Materialet blev læst gentagne gange for at finde de emner og kategorier, som fremstod som relevante for besvarelsen af undersøgelsens mål, med fokus på tre nøglemomenter: før, under og efter semestret.

\section{Analyse og diskussion}

\section{Før profilsemestret}

Ved besvarelsen af den første refleksionsøvelse på den første undervisningsgang viste de otte studerende ret stor enighed i deres tanker omkring sproglæring. Svarene til de lukkede spørgsmål i spørgeskemaet viser meget lidt spredning (se Tabel 1 ovenfor): I de fleste spørgsmål er der mindst fem studerende, som har valgt den samme valgmulighed, og generelt er maks. tre ud af fem valgmuligheder benyttet (med undtagelse af spørgsmålene 8 og 16) med konsekvent fravælgelse af de ekstreme valg: meget enig og især meget uenig (sidstnævnte kun valgt i to spørgsmål af i alt tre studerende). Denne tendens til at svare med den neutrale mulighed (3) eller de nærliggende 2 og 4 kan have flere fortolkninger. Det kan forstås som tegn på usikkerhed (Cota Grijalva \& Ruiz-Esparza Barajas, 2013) - og én studerende undskylder sig således med en lille note på spørgeskemaet: I am sorry for all the 3's - men man kan også se det som et tegn på, at det er svært at svare uden kontekst, da svaret kan afhænge af mange forskellige faktorer. I transskriptionerne fra den første grupperefleksion, hvor de studerende reflekterer over deres svar, kan man finde evidens for begge fortolkninger: I wasn't sure about it, so I put it in the middle one again ${ }^{4}$, men også Midt $i$ - altså jeg synes lidt, at det kommer an på så meget.

I denne første gruppediskussion er der et emne, som meget hurtigt kommer til at optage en del af samtalen, og det er grammatikundervisning. Denne interesse for grammatikkens funktion i sprogundervisning og -læring afspejler den centrale rolle, som grammatikundervisning har haft i den fagdidaktiske litteratur (Fernández, 2014), og her er de fleste studerende enige om, at der skal undervises eksplicit i grammatik (spørgsmål 12), men at grammatikken ikke er alt (spørgsmål 17). Der viser sig nogle modsigelser i de studerendes svar, som vidner om en vis spænding mellem kommunikativ undervisning og mere traditionel grammatikundervisning: På den ene side fremhæver de studerende den kommunikative tilgang, med anvendelse af sproget ved at tale og lytte, som svar på det åbne spørgsmål om deres mest succesfulde oplevelser med sproglæring. Ligeledes som svar på det åbne spørgsmål, om hvordan de gerne vil lære et nyt sprog, foretrækker de fleste at lære gennem at rejse og bruge sproget (kombineret med undervisning); samtidig nævner de kedelig og irrelevant grammatik som svar på det åbne spørgsmål om deres negative oplevelser med sproglæring. På den anden side, når de svarer på, hvordan de ville undervise andre i deres modersmål, vil de fleste dog undervise i grammatik (nok starte med basisordforråd og -sætninger). Lignende lidt modstridende tanker om grammatik og kommunikativ undervisning er fundet i andre unders $\varnothing$ gelser om lærerkognition blandt lærerstuderende (fx Graus \& Coppen, 2016).

Et andet emne, der optager gruppediskussionen på semestrets første time, er kulturkomponenten i sprogundervisning (spørgsmål 16). Dette er det spørgsmål, som viser mest uenighed blandt de studerende, og en del af forklaringen kan være, at de studerende er usikre på, hvad man mener med kultur:

\footnotetext{
${ }^{4}$ Nogle grupper diskuterede på engelsk, og nogle på dansk. Undervisningen foregik på engelsk.
} 
G: But I'm like, isn't language such a big part of culture? Like by learning the language you also necessarily learn about the culture.

D: But before I started here I didn't know much about the civil war or anything in America, and I kind of could speak American as well...

G: Maybe it depends on the language then.

D: And it depends on what kind of culture. Because if you need to talk about the civil war of course you need to know about it. There are times where you need to know the vocabulary.

G: But also like what part is culture and what part is history. Or is it more like there are some full pass on how you do stuff. Like when you bump into someone you say sorry. Or excuse me. That's more necessary.

H: That's more language than culture then. Also saying "how are you doing?" every time you meet someone. That's another thing when you go to an English-speaking country.

D: There are all those idioms and stuff like that. That you wouldn't know.

G: Yeah and if there are specific words of racism that are kind of bad...

$H$ : Yeah well if you look at it from that point, then I think it is important. But in general you don't need to know everything about a country's culture.

D: I think I thought of it more as history than as culture.

H: Yeah me too. (Optagelse 2)

Usikkerheden omkring den kulturelle/interkulturelle komponent i sprogundervisning er veldokumenteret i litteraturen om lærerkognition, og det gælder ikke alene lærerstuderende men også erfarne lærere (Fernández, 2015), og kulturkomponenten anses som den del, der meget nemt kan blive tilsidesat til fordel for det rent sproglige (Young \& Sachdev, 2011).

Andre emner, der bliver berørt i diskussionen, er anvendelsen af apps, som noget flere studerende fremhæver som værende nyttigt for at lære sprog, og vigtigheden af en god lærer, som bliver nævnt af flere som grunden til deres positive erfaringer med sproglæring. I diskussionen om spørgsmål 18 er det tydeligt, at de studerende er enige om, at der er flere faktorer, der udgør en god lærer, og gode sproglige kompetencer på fremmedsproget er kun én af dem. At være en god formidler og at skabe et godt socialt miljø i klasseværelset er også påskønnet. Flere studerende fortæller anekdoter om gode og dårlige lærere, de har oplevet, og emnet virker til at fylde en del i deres tanker om sproglæring. Dette er i overensstemmelse med andre undersøgelser om fx elevmotivation, som viser, at læreren kan være en afgørende faktor (Knudsen, 2017; Pedersen, 2017).

Alt i alt kan man sige, at disse studerende kom til profilsemestret med enslydende tanker omkring sproglæring og med visse usikkerheder. Enigheden kan forklares ved, at de deler lignende livshistorier om sproglæring, da de alle har lært sprog i det danske skolesystem, og vi ved fra forskningen i lærerkognition, at det er præcis disse erfaringer med egen læring, som er med til at forme vores tanker om, hvad der er den rigtige og forkerte måde at undervise i og lære sprog (Lortie, 1975; Borg, 2003; 2015). Det er interessant, at de studerende ikke snakker om det, de har lært på universitetet (med undtagelsen af én studerende, som næv- 
ner, at han har haft noget om alder og sproglæring (jf. spørgsmål 6) i et fag på universitetet: Jeg kan bare huske, at jeg blev proesenteret med en masse undersøgelser). Manglende referencer til teorier og akademisk litteratur stemmer overens med litteraturen om lærerkognition, som viser, at lærernes tanker udformes tidligt (Pajares, 1992, s. 328), og at lærerne sjældent refererer til didaktisk litteratur (Ebsworth \& Schweers, 1997 i Borg, 2015).

\section{I løbet af profilsemestret}

I løbet af semestret blev de studerende udsat for tre forskellige typer af gruppeopgaver, hvor de skulle: 1) svare på teoretiske spørgsmål, hvor de skulle forholde sig til den akademiske litteratur ( $\mathrm{fx}$ "What contribution has behaviorism made to our understanding of how languages are learned?"); 2) reflektere over forskellige aspekter af sproglæring og dermed eksplicitere egne tanker ( $\mathrm{fx}$ "How important is the teaching of culture in the context of L2 teaching as compared to other components of the language in your opinion and in real practice you can include insights from your observations at the practicum" eller "Complete the learning style test that I enclose and based on your result, how do you think your particular learning style can affect your teaching style?"); 3) designe kommunikative tasks med forskellige fokusområder ( $\mathrm{fx}$ "design a writing task that may also incorporate elements of reading, is collaborative, is multimodal and includes some element of feedback").

Disse opgaver havde til formål netop at give de studerende mulighed for at italesætte deres tanker vedr. sproglæring og diskutere og sammenligne dem med deres klassekammerater. Dermed ville de forhåbentligt nå frem til en ny forståelse - i overensstemmelse med den fagdidaktiske litteratur om lærerkognition, som peger på vigtigheden af at diskutere eksisterende tanker i løbet af læreruddannelsen (Pajares, 1992; Fives \& Buehl, 2012). De mere praktiske og kreative opgavers sigte var at give de studerende mulighed for at omsætte tankerne til praksis, dog stadig kun "hypotetisk" praksis, da de designede tasks ikke nødvendigvis skulle afprøves i virkeligheden (nogle tasks blev dog faktisk afprøvet i gymnasiepraktikken).

En gennemgang af besvarelserne fra de forskellige typer øvelser viser en vis fremgang i de studerendes sikkerhed samt voksende forståelse. Fx kan man i de kreative opgaver om taskdesign ane en forskel mellem de første tasks og de efterfølgende, og en del af forbedringen kan måske relateres til de klassediskussioner, hvor hver designet task blev kommenteret og undersøgt på basis af kravene til en kommunikativ task (= at der er et informationshul, at eleverne kan anvende egne sproglige ressourcer, at der er fokus på indhold, og at der er et kommunikativt output (Svendsen Petersen, 2001)).

I undervisningsgang nr. 5 blev de studerende bedt om at diskutere deres besvarelser fra spørgeskemaet fra undervisningsgang nr. 1 i grupper for at se, hvorvidt de stadig ville svare på samme måde. I optagelserne fra denne gruppediskussion bliver det tydeligt, at de studerende mener, at det er for tidligt til at kunne revurdere deres tanker, især fordi de ikke selv har kastet sig ud i praksis:

\section{- I just feel like I still need a little more information to really feel sure about this}

- But we've already got a lot of information, it's just that we don't know how to feel about that information yet. (Optagelse 4)

- Det er jo bare tekster i sidste ende, og jeg tror, at noget af det skal du selv ud at prøve, før at det... giver mening. (Optagelse 3) 
Ikke desto mindre er der én kommentar, som gentager sig i optagelserne: At det hele er blevet mere "nuanceret". Denne nuancering udmunder sig i, at nogle studerende føler, at de nu har forstået, at der ikke kun er én rigtig måde at gøre tingene på:

- Jeg synes også, som du siger, at det er bare blevet mere nuanceret. Altså jeg ikke ved rigtig sådan helt sådan... Der er i hvert fald et par stykker, hvor jeg toenker sådan: "Nå, men det kunne godt voere, at det ikke var helt rigtigt, det jeg egentlig havde tænkt". (Optagelse 3)

- I think I am more lenient now than I was before because I've seen all the methods and also just looking at the tasks today, the way that you can do tasks in the classroom that was really interesting. I think that might have shifted it a bit for me. (Optagelse 4)

I sidste undervisningsgang blev der plads til en lignende gruppediskussion, denne gang med fokus på tankerne omkring kulturkomponenten, som var timens emne. Igen er "nuancering" et nøgleord i forbindelse med de studerendes udvikling:

- Jeg har loert, at man skal voere lidt mere påpasselig på, hvad det er for nogle stereotyper, man giver videre til eleverne.

- Det handler om at voere nuanceret, tror jeg. Så meget man nu kan, og så ikke have berøringsangst. (Optagelse 5)

Men også en ny bevidsthed om kulturkomponentens rolle kommer til syne:

- Det var det her med, at i loereplanerne at det kommer til at have så stor betydning, at sådan et kulturelt element skal med. Det synes jeg også var meget overraskende det her. Altså. Det er naesten sådan opdragende facetter (...), at de bliver bedre mennesker, og at man skal bruge kulturen måske, og ja, så undervisningen i det til at få dem derhen.

- For at blive mere nuancerede og blive ordentlige mennesker, der kan rumme flere... altså det giver god mening, men man... hold da op. Det er godt nok en stor mundfuld i en loereplan, man lige har ansvaret for. (Optagelse 5)

Ved slutningen af semestret kan man også mærke i de studerendes kommentarer, at praksis har sneget sig ind og påvirket deres kognition. Fx bruger gruppen en del diskussionstid på at snakke om, hvordan man skal forholde sig til kulturkomponenten, når man har en meget multikulturel elevgruppe - og dette på basis af én af de studerendes erfaring fra sin praktik.

Efter profilsemestret

Ca. to uger efter endt undervisning i profilsemestret skulle de studerende aflevere deres eksamensportfolio, og for denne analyse er der interessant materiale at hente i både refleksionsessayet, hvor de studerende skriver deres vurdering af semestrets samlede udbytte, og praktikrapporten, hvor de er bedt om at forholde sig til den observerede og selvudførte undervisning på basis af relevant teoretisk litteratur fra semestret. Fælles for de otte studerende er, at de vurderer semestrets udbytte meget positivt. Det er uden tvivl gymnasiepraktikken, som især vækker begejstring, men de påskønner også de teoretisk didaktiske forløb som nødvendig basis:

G: What I learned most from was being out in my practicum, but I would not have felt terribly comfortable out there, if I did not feel I had a good theoretical background to back up what I was doing. 
Semestret virker til at have haft en indflydelse på disse studerendes viden og overbevisninger vedr. sproglæring på forskellige måder. For det første introducerede det fagdidaktiske kursus aspekter om deres fag, som de ikke var blevet præsenteret for tidligere i deres studium:

A: The fact that there are so many different aspects to second language teaching, and teaching in general, has been a real eye-opener. As I had not had similar subjects before, it was very relevant to get some theory on how to deal with teaching in practice.

H: Before this course, my own abilities in regards to my studies in English and classical studies had been very much in focus. When I thought about teaching, I mostly thought about all the interesting components of my subject. The aspect of student learning and all the different ways of teaching had not really crossed my mind.

Ligesom var tilfældet i løbet af semestret i de studerendes diskussioner, fokuserer disse slutrefleksioner om især tre aspekter: kommunikativ undervisning, tilgangen til grammatik, samt interkulturel kompetence:

F: Da jeg selv er opdraget i grammatik og overscettelses-metoden og den generative-teori så var det befriende i SLA-forløbet at få proesenteret et mere nuanceret syn på sprogtilegnelsen (...), hvor de grammatiske foenomener proesenteres $i$ en relevant kommunikativ kontekst.

E: I noticed an ongoing theme through all the English classes I observed, namely a strong presence of the communicative approach. (...) When I think back on my English classes in gymnasium, I remember fluency and communication skills as important, but it is not until after I have tried being on the teacher's side of the classroom that I see just how prominent the oral part of English language teaching and learning is.

F: Denne opdagelsesproces blev på glimrende vis stilladseret af vores lektion om interkulturel kompetence. Efter forløbet er jeg således også langt bedre klaedt på i forhold til at drage nytte af de forskelle, som ifølge Claire Kramsch opstår og vedligeholdes gennem sproglige/symbolske interaktioner mellem mennesker. I min praktik hostede jeg også brugbare erfaringer $i$ forhold til at kunne begå mig $i$ det kulturelt heterogene klassevoerelse.

En gennemgang af besvarelserne viser tydeligt, at det fagdidaktiske kursus ikke alene har bidraget med en introduktion til sproglærings- og didaktiske teorier, men gennem de stillede opgaver, klassediskussionerne og familiariseringen også med begrebet "kommunikativ task":

D: It opened up some great discussions and we started sharing our opinions of how we would do things when we get a job sometime in the near future. This notion of sharing our experiences and ideas is a very valuable lesson to have learned, because we will need to do this in our future jobs.

F: Derncest fandt jeg også brugbart at arbejde i praksis med Ellis' begreb om Task-baseret loering. Det gav mig en konkret model for hvordan den kommunikative undervisning kan udformes i praksis. Sammen med Klafkis alment didaktiske model, forkortet FIMME på dansk, har jeg nu langt bedre mulighed for at tilretteloegge kvalitets undervisning.

De studerendes svar vidner også om tilegnelsen af et fælles fagligt sprog. De har nu begreber, de kan bruge for at snakke om de forskellige aspekter af sprogundervisning og for at analysere deres observationer i gymnasiepraktikken samt deres egen undervisning: 
$D$ : The teaching style that I observed with XX was influenced by the communicative approach, and made use of both Focus on Form and Focus on Forms centered teaching.

Dette faglige sprog, som også afspejler en tilegnet pedagogical content knowledge (Shulman, 1996), kan ifølge lærerkognitionslitteratur være med til at udforme de kommende læreres professionelle identitet. Desuden er der i nogle studerende tegn på en spontan erkendelse af deres "apprenticeship of observation", måske mest elokvent i følgende citat:

F: Helt overordnet har jeg under forløbet på undervisningsprofilen fået transformeret mine forestillinger om det at vaere underviser, sådan at jeg nu er $i$ stand til teoretisk at kvalificere de sekvenser som kommer til at vcere grundstenene i min undervisning med udgangspunkt i elevernes behov og motivation, loererplanernes krav og mine kompetencer og passioner. Hvor jeg før forløbet ubevidst havde opereret med fagformidler-modellen og den dertil hørende forestilling om at viden uproblematisk flyder fra underviseren til eleven, har jeg gennem forløbet og i min praktik erfaret at det at vore underviser fordrer en refleksiv tilgang til egen praksis (...) Iscer introduktionen til det sociokulturelle paradigme med dets insisteren på at loeringen primœert foregår i et socialt samspil mellem mennesker, der handler i kraft af vores faelles sprog. Dette fokus fik mig til for alvor at få øjnene op for elevens situation og fordringer. Hvor jeg før uden at toenke over det var tilbøjelig til at hoevde, at en stoerk videns base ville vore tilstrcekkelig for en underviser til at sikre god undervisning. Jeg kan nok ikke i den sammenhaeng udelukke, at jeg ubevidst har overtaget nogle af mine tidligere og nuvarende underviseres tilgange.

Alt i alt har profilsemestret ikke alene kvalificeret de studerende teoretisk og praktisk, men har også bidraget til at bekræfte/bestemme deres fremtidige karrierevalg, som følgende udsagn viser:

D: The internship has confirmed my choice of career.

E: It gave me a much clearer picture of what it is like to be a teacher than I had beforehand. (...) It is lovely reassuring to know that I have chosen the right education and the right career path.

Ét år efter

Fem ud af de otte studerende mødte op til et interview ét år efter, kurset var afsluttet (de resterende tre var enten syge, bortrejste eller ikke til rådighed). Alle fem fremmødte havde brugt året på at skrive deres speciale (dvs. de var alle blevet kandidater), og tre af dem havde fået vikarjobs som gymnasielærere, mens to var jobsøgende og havde ikke fået mere undervisningserfaring (eller meget lidt) siden praktikken året før. Set i bakspejlet var det fælles for alles vurdering af profilsemestret, at det havde været yderst nyttigt, og at de ikke ville have undværet det. En af de studerende gav udtryk for, at profilsemestret skulle været kommet tidligere i studiet:

E: Jeg synes jo, at hele min universitetsuddannelse egentlig ikke ledte hen imod, at jeg skulle undervise, som sådan. Det er først kommet på profilsemestret. Og selvom jeg har vidst fra starten af, at det var det, jeg ville, så har jeg jo haft en masse fag, som bare var dem, jeg skulle igennem. (...) Fordi jeg kun har haft den der profil et semester, inden jeg skrev speciale... jeg har ikke voeret inde i alle de der begreber og ting og sager, som kunne have voeret rare at have haft fra starten, så man var mere kloedt på til at skulle ud og undervise. 
Indholdsmæssigt virker det som om, at det mest er de mere generelle didaktiske komponenter af profilsemestret, som er præsente i deres tanker. Når de tidligere studerende bliver spurgt om de nøglebegreber, som de har med fra semestrets undervisning, er motivation, variation, medbestemmelse og at skabe trykke rammer gengangere i deres svar. Det er disse aspekter, hvor de tre deltagere, som er i job, har lagt deres kræfter i de meget hektiske første måneder som lærere, og det er også det, de jobsøgende tænker, at de vil fokusere på, når de får lov at undervise.

Til gengæld kniber det meget mere med at huske specifikke didaktiske teorier om fremmedsprog, som har gjort indtryk på dem, og nogle af de centrale komponenter, som havde optaget de studerende gennem semestret (grammatik, ordforråd, interkulturel kompetence, kommunikativ undervisning, herunder kommunikative tasks), var tydeligvis blevet forsømt. I forhold til grammatik vidner deltagernes svar om, at de underviser efter meget mere traditionelle modeller, end dem der blev foreslået, diskuteret og øvet i profilsemestret. Studerende C nævner, at hendes undervisning er "meget klassisk" og følger rækkefølgen i grammatikbogen, "hvor jeg vurderer, at det er nogenlunde sådan, at det stiger lidt i sværhedsgrad". Studerende E nævner, at hun vil arbejde "kronologisk" med grammatik og vil gerne gå igennem alle ordklasser og kommatering; kontekstualiseret grammatik er ikke noget, hun har prøvet.

Ordforrådstilegnelse er ikke noget, som disse nye lærere har fokuseret specifikt på endnu (selvom de gerne vil i fremtiden), og ingen af dem har følt sig sikre nok til at arbejde med kommunikative tasks:

C: Som ny underviser tvivler jeg rigtig meget på, er det nu rigtigt, det jeg gør? Er det godt nok? Der synes jeg, det kan vaere enormt rart at benytte sig af nogle bøger, eller nogle forløb, der er lavet. Jeg har fået nogle af min kollega. Der toenker jeg, at det der med at skulle lave en task, det er også lidt... får de nu noget ud af det? Gør jeg det rigtigt?

Kulturkomponenten har alle tre nye lærere inkluderet i deres undervisning i form af forskellige emner, nogle gange med fokus på information om engelsktalende lande eller en periode (fx 1920'erne), men de forskellige facetter af modeller som Byrams (1997), som blev ekstensivt diskuteret i profilsemestret, har ikke været i fokus.

Disse resultater, som viser at de nye sproglærere pga. tidspres og usikkerhed fokuserer mere på klasseværelsesledelse end konkrete sprogdidaktiske aspekter, stemmer overens med internationale resultater (Numrich, 1996 i Borg, 2015). De sprogdidaktiske aspekter, som var centrale i profilsemestret, er derfor ikke nødvendigvis glemte eller tabte, og de vil forhåbentligt komme i spil hen ad vejen, når der er mere overskud:

E: [om profilsemestrets indhold] Det er meget at få på én gang. Når man så kommer ud, og skal prøve det i praksis, så kan man bare ikke få det hele med fra starten af, selvom man gerne ville. (...) [Om at arbejde med sprogloeringsstrategier] Jeg har, men ikke så meget som jeg gerne ville. Men igen, det har voeret det der med, at det har jeg egentlig ikke haft overskud til. At skulle toenke det ind i alt. Men det kan komme, på et tidspunkt, og det håber jeg da, at det gør.

Deltagerne er derfor glade for, at noget af det samme indhold, som blev gennemgået i profilsemestret, vil blive behandlet igen, når de kommer til Teoretisk Pædagogikum. De ser en mulig gentagelse som en fordel snarere end en ulempe. 
De forsinkede interviews viser, at disse kandidaters - og splinternye sproglæreres - kognition er blevet påvirket af deres profilsemester, men ikke alle disse tanker og den nyligt tilegnede viden afspejles - i følge egne udsagn - i deres praksis, da eksterne faktorer som tidspres og interne faktorer som usikkerhed kan være med til at bremse nogle af de tiltag, som de ellers gerne vil implementere. Dette stemmer overens med det, som vi ved om lærerkognition: At der ikke findes et én-til-én forhold mellem tanker og praksis (Fives \& Buehl, 2012), og at didaktisk fornyelse tager tid (Wagner, 1991).

\section{Sammenfatning}

I denne artikel har jeg forsøgt at belyse, hvordan et semester på universitetet, som er specifikt målrettet til at give kandidatstuderende en didaktisk toning i deres studium, har påvirket en gruppe sprogstuderende. Undersøgelsen af deres tanker før, under og efter semestret samt deres evt. praksis efter overstået studium har vist, at semestret har været et vigtigt studieelement i deres bevidsthed, som de ikke synes, at de ville kunne undvære. De kom til semestret med enslydende tanker og usikkerheder, og de fik gennem forskellige arbejdsformer ny viden om almen- og fagdidaktik - to områder som ellers havde været helt fraværende fra deres studier. Især gymnasiepraktikken gjorde stort indtryk på dem og var med til at bestemme eller bekræfte deres fremtidige karrierevej. Ikke al den nye viden er blevet omsat til praksis i deres første tid som lærere, og det er især elementer som klasseledelse, de har haft mest overskud til at arbejde med. De opnåede resultater i denne undersøgelse stemmer overens med tidligere studier om lærerkognition hos lærerstuderende og viser, at en gymnasieprofil, eller andre former for didaktiske studieelementer, allerede på kandidatstudiet, og før den officielle teoretiske pædagogikumuddannelse for gymnasielærere, er et positivt tiltag, selvom ikke alt den tilegnede viden appliceres i klasseværelset med det samme.

\section{Referencer}

Aarhus Universitet (u.d. a). Profilfag. Lokaliseret den 6. marts 2018 fra http://studerende.au.dk/studier/fagportaler/arts/undervisning/profilfag/

Aarhus Universitet (u.d. b). Undervisning i teori og praksis. Lokaliseret den 6. marts 2018 fra http://kursuskatalog.au.dk/da/course/81062/Undervisning-i-teori-og-praksis

Basturkmen, H. Loewen, S. \& Ellis, R. (2004). Teachers' stated beliefs bout incidental focus on form and their classroom practices. Applied Linguistics, 25(2), s. 243-272.

Borg, S. (1998a). Talking about grammar in the foreign language classroom. Language Awareness, 7, 159-75.

Borg, S. (1998b). Teachers' pedagogical systems and grammar teaching: A qualitative study. TESOL Quarterly, 32 (1), 9-38.

Borg, S. (2001). Self-perception and practice in teaching grammar. ELT Journal, 55(1), 21-29.

Borg, S. (2003). Teacher cognition in language teaching: a review of research on what language teachers think, believe, know and do. Language Teaching, 36, 81-39.

Borg, S. (2006). The distinctive characteristics of foreign language teachers. Language Teaching Research, 10, 3-31. 
Borg, S. 2006 (2015). Teacher cognition and language education. Research and practice. 2. edition. London: Bloomsbury.

Borg, S. (2009). Teacher research in language teaching: A critical analysis (Cambridge Teachers' Conceptions of Research', Applied Linguistics, 30 (3) pp. 355-388.

Borg, S. \& Burns, A. (2008). "Integrating Grammar in Adult TESOL Classrooms." Applied Linguistics, 29, 456-482.

Byram, M. (1997). Teaching and assessing intercultural communicative competence. Bristol: Multilingual Matters.

Børsting, L. D. (2018). Danish Upper Secondary School English Teachers' Cognitions on Learning Strategies. Upubliceret speciale. Aarhus Universitet.

Cota Grijalva, S. \& Ruiz-Esparza Barajas, E. (2013). Pre-service teachers' beliefs about language teaching and learning: A longitudinal study. PROFILE 15, 1, s. 81-95.

Daryai-Hansen, P. \& Henriksen, B. (2017). Lærerkognition som centralt udgangspunkt for en efteruddannelsesmodel til udvikling af lærernes undervisningspraksis. Studier i Loereruddannelse og -profession, 2, nr. 2.

Dörnyei, Z. (2007). Research methods in applied linguistics: quantitative, qualitative, and mixed methodologies. Oxford: Oxford University Press.

Fernández, S. S. (2014). Fokus på form. I H. L. Andersen, S. S. Fernández, D. Fristrup, \& B. Henriksen (red.), Fremmedsprog i gymnasiet: teori, praksis og udsyn (Kapitel 4, s. 43-54). København: Samfundslitteratur.

Fernández, S. S. (2015). Concepciones de los profesores daneses acerca de la competencia intercultural en la clase de español como lengua extranjera. Milli Mála - Journal of Language and Culture, 7, 95-120.

Fives, H. \& Buehl, M. (2012). Spring cleaning for the "messy" construct of teachers' beliefs: What are they? Which have been examined? What can they tell us? I K. Harris, S. Graham \& T. Urdan (eds.) Educational Psychology Handbook. Vol. 2, s. 471-499.

Graden, E. C. (1996). How Language Teachers' Beliefs about Reading Instruction are Mediated by their Beliefs about Students. Foreign Language Annals, 29:3, s. 387-395.

Graus, J. \& Coppen, P. (2016). Student teacher beliefs on grammar instruction. Language Teaching Research, 20(5), s. 571-599.

Hattie, J. (2003). Teachers Make a Difference: What is the research evidence? Presented at the Building Teacher Quality: What does the research tell us ACER Research Conference, Melbourne, Australia: Conference Archive at ACEReSearch. Retrieved from http://research.acer.edu.au/research conference 2003/4/

Kjærgaard, H. W. (2018). Technology-mediated written corrective feedback in the Danish lower secondary classroom. Upubliceret phd-afhandling. Aarhus Universitet.

Knudsen, M.H. (2017). Den motiverende spanskundervisning - et empirisk studie af danske gymnasieelevers motivation for at loere spansk. Upubliceret speciale. Aarhus Universitet.

Kuzborska, I. (2011). Links between teachers' beliefs and practices and research on reading. 
Reading in a Foreign Language. 23: 1, s. 102-128.

Kvale, S. \& Brinkmann, S. (2009). Interview. Introduktion til et håndvcerk. København: Hans Reitzels Forlag.

Lightbown, P. \& Spada, N., 2006- (2011). How languages are learned. (3. edition). Oxford: Oxford University Press.

Lortie, D. C. (1975). Schoolteacher: a sociological study. Chicago: University of Chicago Press.

Meijer, P., Verloop, N. \& Beijaard, D. (1999). Exploring language teachers' practical knowledge about teaching reading comprehension. Teaching and Teacher Education 15, s. 59-84.

Merriam, S. B. (2009). Qualitative research: a guide to design and implementation. San Francisco: Jossey-Bass.

Merriam, S. B., \& Tisdell, E. J., 1955-. (2016). Qualitative research: a guide to design and implementation (4. edition). San Francisco, CA: Jossey-Bass.

Nishimuro, M. (2013) Teacher Cognition and Grammar Teaching in a Japanese High School. JALT Journal, 35, 1, s. 29-50.

Pajares, M. F. (1992). Teachers' Beliefs and Educational Research: Cleaning up a Messy Construct. Review of Educational Research, 62(3), 307-332.

Pedersen, S. (2017). Motivation factors for learning English among Danish upper secondary school students. Upubliceret special. Aarhus Universitet.

Phipps, S. \& Borg, S. (2009). Exploring tensions between teachers' grammar teaching beliefs and practices. System 37, s. 380-390.

Schön, D. (2001). Den reflekterende praktiker. Hvordan professionelle toenker når de arbejder. København: Klim.

Shulman, L. S. (1986). Those who understand: knowledge growth in teaching. Educational Researcher, 15(2), s. 4-14.

Svendsen Pedersen, M. (2001). Task Force. Et bud på kommunikativ sprogundervisning. Sprogforum 20, 7, s. 7-19.

Syddansk Universitet (u.d.), Teoretisk Pædagogikum. Lokaliseret den 6. marts 2018 fra https://www.sdu.dk/da/Om_SDU/Institutter_centre/lkv/Uddannelse/Paedagogikum1

Undervisningsministeriet (u.d.) Pædagogikum ved de Gymnasiale Uddannelser. Uddannelsesguiden. Lokaliseret den 6. marts 2018 fra https://www.ug.dk/uddannelser/andreerhvervsrettedeuddannelser/andreuddpaedog psyk/paedagogikum-ved-de-gymnasiale-uddannelser

Vijayavarathan, K. (2017) Teacher cognition of grade 8 teachers on teaching speaking in English as a foreign language in The Faroe Islands and its impact on teachers' pedagogical praxis: seven case studies. Upubliceret phd-afhandling. Aarhus Universitet.

Wagner, J. (1991). Innovation in Foreign Language Teaching. I R. Phillipson et al. (eds.). Foreign/Second Language Pedagogy Research. Multilingual Matters, pp. 288-306.

Woods, D. (1996). Teacher cognition in language teaching: beliefs, decision-making, and class- 
room practice. Cambridge: Cambridge University Press.

Xiaohui, H. \& Li, S. (2011) Teacher Cognition of Intercultural Communicative Competence in the Chinese ELT Context. Intercultural Communication Studies XX: 1, s. 175-192.

Young, T. \& Sachdev, I. 2011. Intercultural communicative competence: exploring English language beliefs and practices. Language awareness, Vol.20, 2, 81-98. 